Original Research Paper

\title{
CpG Oligodeoxynucleotides Debate the Damaging Action of Cisplatin on Immune Cell DNA: A PCR Array Application on Repair Genes Expression
}

\author{
${ }^{1}$ Naglaa Fathy Alhusseini, ${ }^{1}$ Amal Abo El-Fadl, ${ }^{2}$ Shabaan Hemada, \\ ${ }^{3}$ Mohamed Abo Salem, ${ }^{1}$ Yasmin Marei, ${ }^{4}$ Olla Khalifa and ${ }^{1}$ Amal Idris \\ ${ }^{1}$ Department of Medical Biochemistry and Molecular Biology, Faculty of Medicine, Benha University, Egypt \\ ${ }^{2}$ Department of Animal Wealth Development, Faculty of Veterinary Medicine, Alexandria University, Egypt \\ ${ }^{3}$ Department of Toxicology and Forensic Medicine, Faculty of Veterinary Medicine, Benha University, Egypt \\ ${ }^{4}$ Department of Animal Wealth Development, Faculty of Veterinary Medicine, Benha University, Egypt
}

\author{
Article history \\ Received: 09-05-2016 \\ Revised: 12-07-2016 \\ Accepted: 13-07-2016 \\ Corresponding Author: \\ Naglaa Fathy Alhusseini \\ Department of Medical \\ Biochemistry and Molecular \\ Biology, Faculty of Medicine, \\ Benha University Egypt \\ Email: nagla.alhusseini@fmed.bu.edu.eg
}

\begin{abstract}
Synthetic Oligodeoxynucleotides (ODN) expressing $\mathrm{CpG}$ motifs (CpG-ODN) mimic the immunostimulatory activity of bacterial DNA and are commonly used to activate Toll Like Receptor 9 (TLR9) for therapeutic applications. CpG-ODN can counteract the activity of DNAdamaging chemotherapy and radiation therapy on immune cell and enhance immunity in preclinical mouse models. We hypothesized that these actions of CpG-ODN on immune cells are expressed by modulation of DNA repair genes. We conducted a PCR array analysis of DNA repair genes expression in splenocytes obtained from mice injected intraperitoneally with CpG-ODN and/or Cisplatin. CpG-ODN modulate expression of DNA repairing genes inducing down regulation in most of DNA repairing genes but up regulate some genes participate in biological processes suggesting the role of $\mathrm{CpG}-\mathrm{ODN}$ in these processes. Cisplatin had an effect on expression of DNA repairing genes inducing up regulation of most genes implicated in repair of toxic effect of Cisplatin. We concluded that the effect of CpG-ODN in elimination of DNA damaging activity of Cisplatin on immune cells appear as counteracting and normalizing the modulation of repair genes expression occurred by Cisplatin.
\end{abstract}

Keywords: CpG, ODN, Cisplatin, DNA Repair Genes, Gene Expression, PCR Array Technique, TLR9, Immune Cells

\section{Introduction}

CpG-Oligodeoxynucleotides (CpG-ODNs) are synthetic DNA sequences that mimic bacterial DNA and are recognized by the Toll-Like Receptor 9 (TLR9). (CpG-ODNs) can stimulate the immune system via interaction with Toll-like receptor 9 (De Cesare et al., 2016) and induces the production of interferon- $\alpha$ and chemokines, leading to the activation of a Th1 immune response. Therefore, synthetic equivalents of bacterial DNA (CpG oligodeoxynucleotides) are considered to be promising immunomodulators and have been developed for clinical applications (Iho et al., 2015). CpG-ODN may be more useful as a component of multi agent therapy for cancer rather than as a single agent. Because chemotherapy is known to be immunosuppressive, it is advisable to combine chemotherapy with TLR9 stimulation during treatment (Vollmer and Krieg, 2009). Particular clinical interest now revolves around TLR9, which is expressed not only on cells of the immune system but also on endothelial cells, fibroblasts and epithelial cells and which recognizes bacterial and viral DNA with unmethylated $\mathrm{CpG}$ motifs (Sommariva et al., 2011). Local, but not systemic and daily, but not weekly, stimulation of immune effectors cells by CpG-ODN targeted immunotherapy modulates genes involved in DNA repair, increasing their expression in TLR9expressing immune cells but down regulating their expression in tumor cells and thereby increasing sensitivity to DNA-damaging chemotherapeutic agents (De Cesare et al., 2010). TLR may both up regulate and down regulate distinct DNA repair proteins its exact role in DNA repair remains unclear (Ahmad et al., 2014). 
Chemotherapy, using the cytotoxic drugs to kill cancer cells, is one of the principal approaches of cancer management over the past years (Xing et al., 2014). Chemotherapeutic drugs result in cancer cell damage due to their strong interaction with DNA (Ilkhania et al., 2016). However, the conventional systemic chemotherapy may result in unacceptable side effects (Jiang et al., 2016). Inherent and acquired resistance to chemotherapy may limit its effect or even leads to treatment failure (Wang et al., 2016). Particular attention in studies of new anticancer drugs has been paid to increase the drug efficacy toward killing cancer cells while limiting their devastating effects on healthy cells (Holohan et al., 2013).

Cisplatin cis-diamminedichloroplatinum (II) is a chemotherapy drug. It was the first member of a class of platinum-containing anti-cancer drugs, which now also includes carboplatin and oxaliplatin (Apps et al., 2015). It make crosslink with the purine bases on the DNA; interfering with DNA repair mechanisms, causing DNA damage and subsequently inducing apoptosis in cancer cells (Dasari and Tchounwou, 2014). Repair of Cisplatin lesion conducted through single strand damage repair mechanism (Caldecott, 2008), double strand break repair mechanism (Salomoni, 2013) and translesion synthesis mechanism (Jackson and Bartek, 2009). Many mechanisms of cisplatin resistance including changes in cellular uptake and efflux of the drug, increased detoxification of the drug, inhibition of apoptosis and increased DNA repair (Stordal and Davey, 2007).

The detection of DNA damage is the key challenge in studies of mutations, carcinogenesis and aging (Hepel et al., 2012). In response to DNA damage, the cell can activate DNA repair systems and enter cell cycle arrest in order to limit further damage. Thus, DNA repair pathways modulate the efficacy of cancer therapy (Ganguly et al., 2016).

The current study aimed to clarify the role of CpGODN in combination with "Cisplatin" as chemotherapy on expression of different DNA repair genes in mice immune cells, using PCR-array technique that may provide a promising therapeutic strategy in cancer treatment through enhancement the immune response.

\section{Subjects and Methods}

\section{Experimental Animals}

Thirty two female Albino mice aged 8 weeks and weighted (20-25 g) at the beginning of the experiment. Mice were obtained from Lab Animal Care Center, Faculty of Veterinary Medicine (Benha University). Animals were kept for one week before experiment to acclimatize to the laboratory conditions. The management was kept constant throughout the experimental period. Water and normal balanced ration was offered ad-libitum and was re-newed every day.
Cages were cleaned regularly in which mice were moved to completely clean cages two times a week.

Mice were divided into 4 groups; each group consisted of 8 mice. The first group was kept as a control group given $200 \mathrm{uL}$ normal saline I/P. The second group II given $20 \mathrm{ug} /$ mouse $\mathrm{CpG}-\mathrm{ODN} \mathrm{I} / \mathrm{P}$. The third group III was given $3 \mathrm{mg} / \mathrm{kg}$.B.wt Cisplatin I/P. The fourth group IV was given $\mathrm{CpG}-\mathrm{ODN} \mathrm{I} / \mathrm{P}$ in addition to Cisplatin $\mathrm{I} / \mathrm{P}$ by the same doses in second and third groups. Animal were sampled after 4 weeks from the beginning of experiment.

\section{Cisplatin}

It was manufactured by MYLAN S.A.S. France as concentrated solution $1 \mathrm{mg}$ cisplatin $\backslash 1 \mathrm{~mL}$ to obtain the dose needed ( $3 \mathrm{mg} \backslash \mathrm{kg}$.B.wt) taken $60 \mathrm{uL}$ from the stock diluted by $200 \mathrm{uL}$ saline.

\section{CpG-ODN Phosphorothioated 1826}

It was manufactured by Trilink Biotechnologies Company, San Diego, CA, USA in lyophilized solid form. Its sequence 5-TCC ATG ACG TTC CTG ACG $\mathrm{TT}-3$, to obtain the dose needed (20 ug/mouse) (Sommariva et al., 2013)

\section{Tissue Handling}

Animals were scarified and spleens were taken immediately placed in Cryo tubes and stored in RNA Later solution (by $10 \mu \mathrm{L}$ per $1 \mathrm{mg}$ of tissue) (Qiagen$\mathrm{GmbH}$ Hilden, Germany) at $-80^{\circ} \mathrm{C}$.

\section{Total RNA Extraction}

Total RNA extraction was done by using total RNA Purification Kit from Jena Bioscience $\mathrm{GmbH}$ and according to the manufacturer instructions, about $30 \mathrm{mg}$ tissue put in a micro centrifuge tube with $300 \mu \mathrm{L}$ of lysis buffer containing 2 Mercapto Ethanol (2ME) was homogenized using rotor Tissue Ruptor (Qiagen, $\mathrm{GmbH}$ ) (Yousef et al., 2014). Ten $\mu \mathrm{L}$ RNA from each sample of the same group are mixed to make a pool for each group.

\section{Spectrophotometric Quantification of RNA}

The concentration and purity of RNA were determined by measuring the absorbance in a Nanodrop spectrophotometer 2000 USA. An absorbance reading of 1.0 at $260 \mathrm{~nm}$ in a $1 \mathrm{~cm}$ detection path corresponds to an RNA concentration of $40 \mu \mathrm{g} \mathrm{m}^{-1}$. Pure RNA has an $\mathrm{A}_{260} / \mathrm{A}_{280}$ ratio of 1.8-2.0.

\section{Assessment of DNA Repair Genes Expression}

\section{Synthesis of cDNA using RT First Strand Kit (Qiagen, GmbH)}

According to the manufacturer instruction, about 5 $\mu \mathrm{g}$ RNA used with genomic DNA elimination mix and the $10 \mu \mathrm{L}$ from this mix used for each sample in reverse transcription mix. 


\section{Real-Time PCR for RT2 Profiler PCR Array}

About $25 \mu \mathrm{L}$ PCR components mix was added to each well of the RT2 Profiler PCR Array. The real-time cycler was programmed as $95^{\circ} \mathrm{C}$ for $10 \mathrm{~min}$ followed by 40 cycles of $95^{\circ} \mathrm{C}, 15 \mathrm{sec}$ then $60^{\circ} \mathrm{C}$ for $1 \mathrm{~min}$.

\section{Data Analysis and Statistics}

Calculate the Threshold Cycle $(\Delta \mathrm{CT})$ for each well using the real-time cycler software. Export the CT values for all wells to a blank Excel ${ }^{\circledR}$ spreadsheet for use with the SABioscience PCR Array Data Analysis Template Excel or Web-based software. Dissociation (melting) curve analysis was performed to verify PCR specificity. A melting curve program was run and generated a first derivative dissociation curve for each well using the real-time cycler software. The fold-change for each gene calculated using the formula: $2\left(^{-\Delta \Delta C T)}\right.$ (Livak and Schmittgen, 2001).

The $p$ values are calculated based on a Student's ttest of the replicate $2^{\wedge}($-Delta $\mathrm{Ct})$ values for each gene in the control group and treatment groups and $\mathrm{p}$ values less than 0.05 are indicated in red.

\section{Results}

The comparison of gene expression of all DNA repair genes among the four groups summaries in the cluster gram (Fig. 1) which performs non-supervised clustering of the entire dataset to display a heat map indicating co-regulated DNA repair genes across all studied groups.

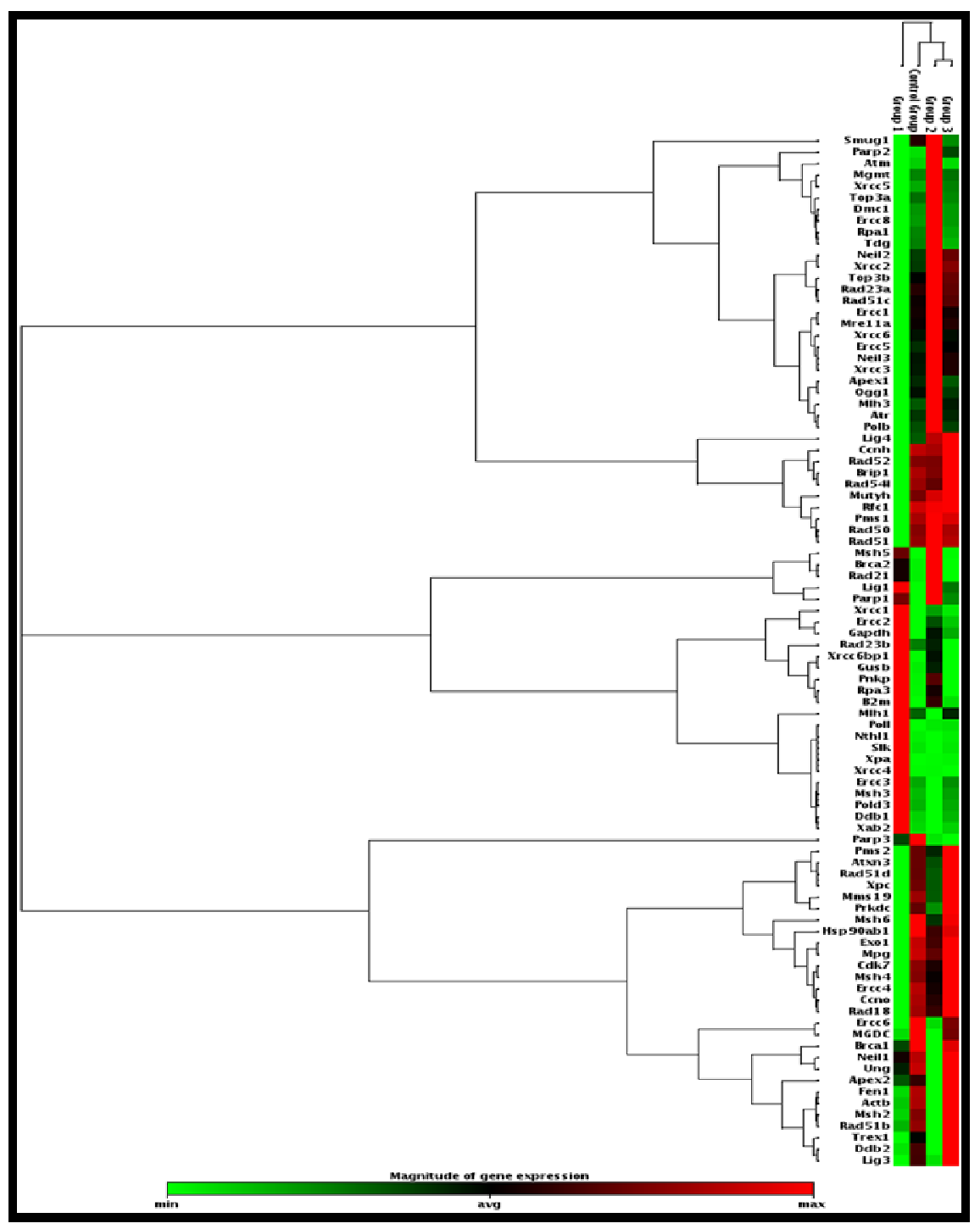

Fig. 1. The cluster gram of co-regulated DNA repair genes across all studied groups. The magnitude of gene expression in each gene is represented by degree of color from red (maximum up-regulation) passing to black (no change) and green (minimum down-regulation 
Naglaa Fathy Alhusseini et al. / American Journal of Biochemistry and Biotechnology 2016, 12 (3): 159.170 DOI: $10.3844 /$ ajbbsp.2016.159.170

Table 1. Fold changes, $\mathrm{p}$ values and fold regulation of the DNA repair genes expression in treated groups compared to control one

\begin{tabular}{|c|c|c|c|c|c|c|c|c|c|}
\hline \multirow[b]{2}{*}{$\begin{array}{l}\text { Gene } \\
\text { symbol }\end{array}$} & \multicolumn{3}{|c|}{ Group 1/control group } & \multicolumn{3}{|c|}{ Group 2/control group } & \multicolumn{3}{|c|}{ Group 3/control group } \\
\hline & $\begin{array}{l}\text { Fold } \\
\text { change }\end{array}$ & $\begin{array}{l}\text { T-test } \\
\text { p value }\end{array}$ & $\begin{array}{l}\text { Fold up/ } \\
\text { down } \\
\text { regulation }\end{array}$ & $\begin{array}{l}\text { Fold } \\
\text { change }\end{array}$ & $\begin{array}{l}\text { T-test } \\
\text { p value }\end{array}$ & $\begin{array}{l}\text { Fold up/ } \\
\text { down } \\
\text { regulation }\end{array}$ & $\begin{array}{l}\text { Fold } \\
\text { change }\end{array}$ & $\begin{array}{l}\text { T-test } \\
\text { p value }\end{array}$ & $\begin{array}{l}\text { Fold up/ } \\
\text { down } \\
\text { regulation }\end{array}$ \\
\hline Apex1 & 0.14 & 0.016 & -7.23 & 2.19 & 0.041 & 2.19 & 0.81 & 0.417 & -1.23 \\
\hline Apex2 & 0.67 & 0.557 & -1.50 & 0.24 & 0.031 & -4.24 & 1.52 & 0.210 & 1.52 \\
\hline Atm & 0.59 & 0.126 & -1.70 & 5.33 & 0.049 & 5.33 & 0.90 & 0.632 & -1.11 \\
\hline Atr & 0.40 & 0.043 & -2.51 & 1.92 & 0.170 & 1.92 & 1.04 & 0.995 & 1.04 \\
\hline Atxn3 & 0.15 & 0.017 & -6.74 & 0.57 & 0.251 & -1.75 & 1.36 & 0.330 & 1.36 \\
\hline Brcal & 0.40 & 0.050 & -2.50 & 0.06 & 0.012 & -17.22 & 0.95 & 0.737 & -1.06 \\
\hline Brca2 & 2.53 & 0.042 & 2.53 & 3.89 & 0.036 & 3.89 & 0.94 & 0.711 & -1.07 \\
\hline Brip1 & 0.14 & 0.017 & -7.19 & 0.91 & 0.942 & -1.10 & 1.17 & 0.670 & 1.17 \\
\hline Ccnh & 0.52 & 0.343 & -1.94 & 0.98 & 0.924 & -1.03 & 1.07 & 0.910 & 1.07 \\
\hline Ccno & 0.20 & 0.021 & -5.07 & 0.75 & 0.584 & -1.34 & 1.16 & 0.690 & 1.16 \\
\hline Cdk7 & 0.15 & 0.017 & -6.74 & 0.76 & 0.613 & -1.31 & 1.26 & 0.491 & 1.26 \\
\hline Ddb1 & 3.64 & 0.036 & 3.64 & 0.76 & 0.610 & -1.32 & 1.16 & 0.696 & 1.16 \\
\hline $\mathrm{Ddb} 2$ & 0.33 & 0.038 & -3.05 & 0.28 & 0.050 & -3.62 & 1.42 & 0.292 & 1.42 \\
\hline Dmc1 & 0.20 & 0.021 & -5.09 & 4.13 & 0.024 & 4.13 & 0.96 & 0.762 & -1.05 \\
\hline Ercc1 & 0.17 & 0.019 & -5.90 & 1.72 & 0.223 & 1.72 & 1.00 & 0.878 & -1.00 \\
\hline $\operatorname{Ercc} 2$ & 4.42 & 0.032 & 4.42 & 2.17 & 0.049 & 2.17 & 1.36 & 0.347 & 1.36 \\
\hline Ercc3 & 5.57 & 0.011 & 5.57 & 0.09 & 0.015 & -11.42 & 1.28 & 0.469 & 1.28 \\
\hline Erce4 & 0.15 & 0.017 & -6.65 & 0.68 & 0.441 & -1.46 & 1.14 & 0.731 & 1.14 \\
\hline Ercc5 & 0.17 & 0.019 & -5.92 & 2.20 & 0.044 & 2.20 & 1.19 & 0.628 & 1.19 \\
\hline Erce6 & 0.35 & 0.050 & -2.89 & 0.39 & 0.042 & -2.58 & 0.83 & 0.451 & -1.21 \\
\hline Ercc8 & 0.19 & 0.020 & -5.40 & 4.41 & 0.050 & 4.41 & 1.01 & 0.911 & 1.01 \\
\hline Exo1 & 0.17 & 0.019 & -5.94 & 0.76 & 0.613 & -1.31 & 1.11 & 0.820 & 1.11 \\
\hline Fen 1 & 0.12 & 0.015 & -8.36 & 0.04 & 0.011 & -25.03 & 1.18 & 0.644 & 1.18 \\
\hline Lig1 & 3.25 & 0.029 & 3.25 & 3.27 & 0.035 & 3.27 & 1.62 & 0.152 & 1.62 \\
\hline Lig3 & 0.58 & 0.251 & -1.74 & 0.62 & 0.315 & -1.62 & 1.25 & 0.495 & 1.25 \\
\hline Lig4 & 0.29 & 0.031 & -3.51 & 2.22 & 0.044 & 2.22 & 2.51 & 0.023 & 2.51 \\
\hline Mgmt & 0.28 & 0.035 & -3.60 & 3.32 & 0.067 & 3.32 & 1.12 & 0.784 & 1.12 \\
\hline Mlh1 & 3.10 & 0.029 & 3.10 & 0.07 & 0.013 & -14.83 & 1.36 & 0.343 & 1.36 \\
\hline Mlh3 & 0.17 & 0.019 & -5.81 & 2.71 & 0.039 & 2.71 & 1.31 & 0.400 & 1.31 \\
\hline Mms19 & 0.36 & 0.042 & -2.81 & 0.61 & 0.334 & -1.63 & 1.15 & 0.718 & 1.15 \\
\hline Mpg & 0.10 & 0.014 & -9.83 & 0.79 & 0.665 & -1.26 & 1.10 & 0.828 & 1.10 \\
\hline Mre11a & 0.16 & 0.018 & -6.20 & 1.77 & 0.207 & 1.77 & 1.08 & 0.898 & 1.08 \\
\hline Msh2 & 0.15 & 0.018 & -6.51 & 0.05 & 0.012 & -19.51 & 1.32 & 0.397 & 1.32 \\
\hline Msh3 & 4.61 & 0.020 & 4.61 & 0.45 & 0.030 & -2.24 & 1.21 & 0.577 & 1.21 \\
\hline Msh4 & 0.15 & 0.017 & -6.65 & 0.73 & 0.539 & -1.37 & 1.28 & 0.453 & 1.28 \\
\hline Msh5 & 3.15 & 0.031 & 3.15 & 4.05 & 0.025 & 4.05 & 1.01 & 0.923 & 1.01 \\
\hline Msh6 & 0.12 & 0.015 & -8.18 & 0.48 & 0.042 & -2.10 & 0.99 & 0.845 & -1.01 \\
\hline Mutyh & 0.25 & 0.027 & -3.95 & 1.20 & 0.558 & 1.20 & 1.28 & 0.469 & 1.28 \\
\hline Neil1 & 0.91 & 0.844 & -1.09 & 0.77 & 0.633 & -1.30 & 1.04 & 0.987 & 1.04 \\
\hline Neil2 & 0.51 & 0.111 & -1.96 & 1.81 & 0.197 & 1.81 & 1.43 & 0.267 & 1.43 \\
\hline Neil3 & 0.17 & 0.019 & -6.02 & 1.97 & 0.163 & 1.97 & 1.18 & 0.651 & 1.18 \\
\hline Nthl1 & 8.75 & 0.005 & 8.75 & 0.81 & 0.730 & -1.23 & 1.05 & 0.966 & 1.05 \\
\hline Ogg1 & 0.56 & 0.466 & -1.80 & 1.49 & 0.315 & 1.49 & 0.92 & 0.667 & -1.09 \\
\hline Parp1 & 2.40 & 0.043 & 2.40 & 2.91 & 0.036 & 2.91 & 1.43 & 0.279 & 1.43 \\
\hline Parp2 & 0.94 & 0.907 & -1.06 & 1.95 & 0.180 & 1.95 & 1.30 & 0.446 & 1.30 \\
\hline Parp3 & 0.38 & 0.042 & -2.60 & 0.07 & 0.010 & -13.80 & 0.03 & 0.008 & -34.95 \\
\hline Pmsl & 0.18 & 0.020 & -5.45 & 1.17 & 0.592 & 1.17 & 1.10 & 0.836 & 1.10 \\
\hline Pms2 & 0.17 & 0.019 & -5.77 & 0.68 & 0.440 & -1.47 & 1.36 & 0.343 & 1.36 \\
\hline Pnkp & 2.75 & 0.004 & 2.75 & 2.15 & 0.044 & 2.15 & 0.97 & 0.800 & -1.03 \\
\hline Polb & 0.16 & 0.018 & -6.31 & 2.59 & 0.050 & 2.59 & 1.06 & 0.951 & 1.06 \\
\hline Pold3 & 3.90 & 0.041 & 3.90 & 0.50 & 0.050 & -1.98 & 1.06 & 0.954 & 1.06 \\
\hline Poll & 7.03 & 0.006 & 7.03 & 1.21 & 0.538 & 1.21 & 1.32 & 0.398 & 1.32 \\
\hline Prkdc & 0.16 & 0.018 & -6.39 & 0.42 & 0.045 & -2.37 & 1.37 & 0.322 & 1.37 \\
\hline Rad18 & 0.17 & 0.019 & -6.01 & 0.79 & 0.665 & -1.27 & 1.19 & 0.620 & 1.19 \\
\hline $\operatorname{Rad} 21$ & 2.97 & 0.039 & 2.97 & 4.75 & 0.047 & 4.75 & 0.90 & 0.619 & -1.11 \\
\hline $\operatorname{Rad} 23 a$ & 0.35 & 0.044 & -2.86 & 1.49 & 0.315 & 1.49 & 1.14 & 0.752 & 1.14 \\
\hline
\end{tabular}


Naglaa Fathy Alhusseini et al. / American Journal of Biochemistry and Biotechnology 2016, 12 (3): 159.170 DOI: 10.3844/ajbbsp.2016.159.170

\begin{tabular}{|c|c|c|c|c|c|c|c|c|c|}
\hline $\operatorname{Rad} 23 b$ & 1.73 & 0.273 & 1.73 & 1.18 & 0.576 & 1.18 & 0.75 & 0.311 & -1.33 \\
\hline Rad50 & 0.15 & 0.019 & -6.48 & 1.26 & 0.484 & 1.26 & 1.08 & 0.897 & 1.08 \\
\hline $\operatorname{Rad} 51$ & 0.16 & 0.018 & -6.31 & 1.23 & 0.519 & 1.23 & 1.08 & 0.905 & 1.08 \\
\hline $\operatorname{Rad} 51 \mathrm{c}$ & 0.20 & 0.021 & -5.13 & 1.73 & 0.220 & 1.73 & 1.22 & 0.555 & 1.22 \\
\hline $\operatorname{Rad} 51 b$ & 0.81 & 0.908 & -1.23 & 0.77 & 0.627 & -1.30 & 1.06 & 0.941 & 1.06 \\
\hline Rad51d & 0.16 & 0.018 & -6.08 & 0.55 & 0.230 & -1.80 & 1.37 & 0.332 & 1.37 \\
\hline Rad52 & 0.16 & 0.018 & -6.10 & 0.99 & 0.887 & -1.01 & 1.28 & 0.457 & 1.28 \\
\hline Rad541 & 0.18 & 0.020 & -5.43 & 0.89 & 0.896 & -1.13 & 1.20 & 0.604 & 1.20 \\
\hline Rfc1 & 0.09 & 0.013 & -10.79 & 1.08 & 0.726 & 1.08 & 1.09 & 0.853 & 1.09 \\
\hline Rpal & 0.42 & 0.046 & -2.38 & 2.87 & 0.043 & 2.87 & 0.82 & 0.444 & -1.21 \\
\hline Rpa3 & 2.98 & 0.045 & 2.98 & 2.05 & 0.050 & 2.05 & 0.97 & 0.811 & -1.03 \\
\hline Slk & 6.92 & 0.005 & 6.92 & 0.72 & 0.520 & -1.38 & 0.98 & 0.832 & -1.02 \\
\hline Smug1 & 0.28 & 0.033 & -3.52 & 1.54 & 0.286 & 1.54 & 0.56 & 0.114 & -1.78 \\
\hline $\mathrm{Tdg}$ & 0.21 & 0.023 & -4.75 & 3.39 & 0.038 & 3.39 & 0.65 & 0.196 & -1.53 \\
\hline Top3a & 0.32 & 0.036 & -3.16 & 2.73 & 0.045 & 2.73 & 0.87 & 0.556 & -1.15 \\
\hline Top3b & 0.58 & 0.143 & -1.71 & 1.42 & 0.357 & 1.42 & 1.17 & 0.664 & 1.17 \\
\hline Trex1 & 0.50 & 0.050 & -2.00 & 0.50 & 0.050 & -2.02 & 1.52 & 0.194 & 1.52 \\
\hline Ung & 0.52 & 0.128 & -1.91 & 0.06 & 0.013 & -17.84 & 1.12 & 0.795 & 1.12 \\
\hline $\mathrm{Xab} 2$ & 6.27 & 0.001 & 6.27 & 0.60 & 0.289 & -1.67 & 1.08 & 0.893 & 1.08 \\
\hline $\mathrm{Xpa}$ & 9.04 & 0.004 & 9.04 & 1.04 & 0.743 & 1.04 & 1.15 & 0.640 & 1.15 \\
\hline $\mathrm{Xpc}$ & 0.36 & 0.028 & -2.77 & 0.65 & 0.390 & -1.53 & 1.25 & 0.445 & 1.25 \\
\hline Xrcel & 4.96 & 0.006 & 4.96 & 1.75 & 0.203 & 1.75 & 1.15 & 0.637 & 1.15 \\
\hline $\mathrm{Xrcc} 2$ & 0.68 & 0.199 & -1.48 & 1.51 & 0.285 & 1.51 & 1.31 & 0.338 & 1.31 \\
\hline Xrcc3 & 0.19 & 0.013 & -5.20 & 1.98 & 0.153 & 1.98 & 1.19 & 0.551 & 1.19 \\
\hline Xrce4 & 7.77 & 0.020 & 7.77 & 1.05 & 0.743 & 1.05 & 0.97 & 0.833 & -1.03 \\
\hline Xrcc5 & 0.29 & 0.020 & -3.46 & 4.64 & 0.049 & 4.64 & 1.36 & 0.291 & 1.36 \\
\hline Xrce6 & 0.28 & 0.019 & -3.62 & 1.83 & 0.185 & 1.83 & 1.01 & 0.955 & 1.01 \\
\hline Xrcc6bp1 & 89.32 & 0.000 & 89.32 & 42.44 & 0.034 & 42.44 & 0.99 & 0.888 & -1.01 \\
\hline
\end{tabular}

The column of gene symbol referred to symbols of 84 DNA repair genes arranged alphabetically

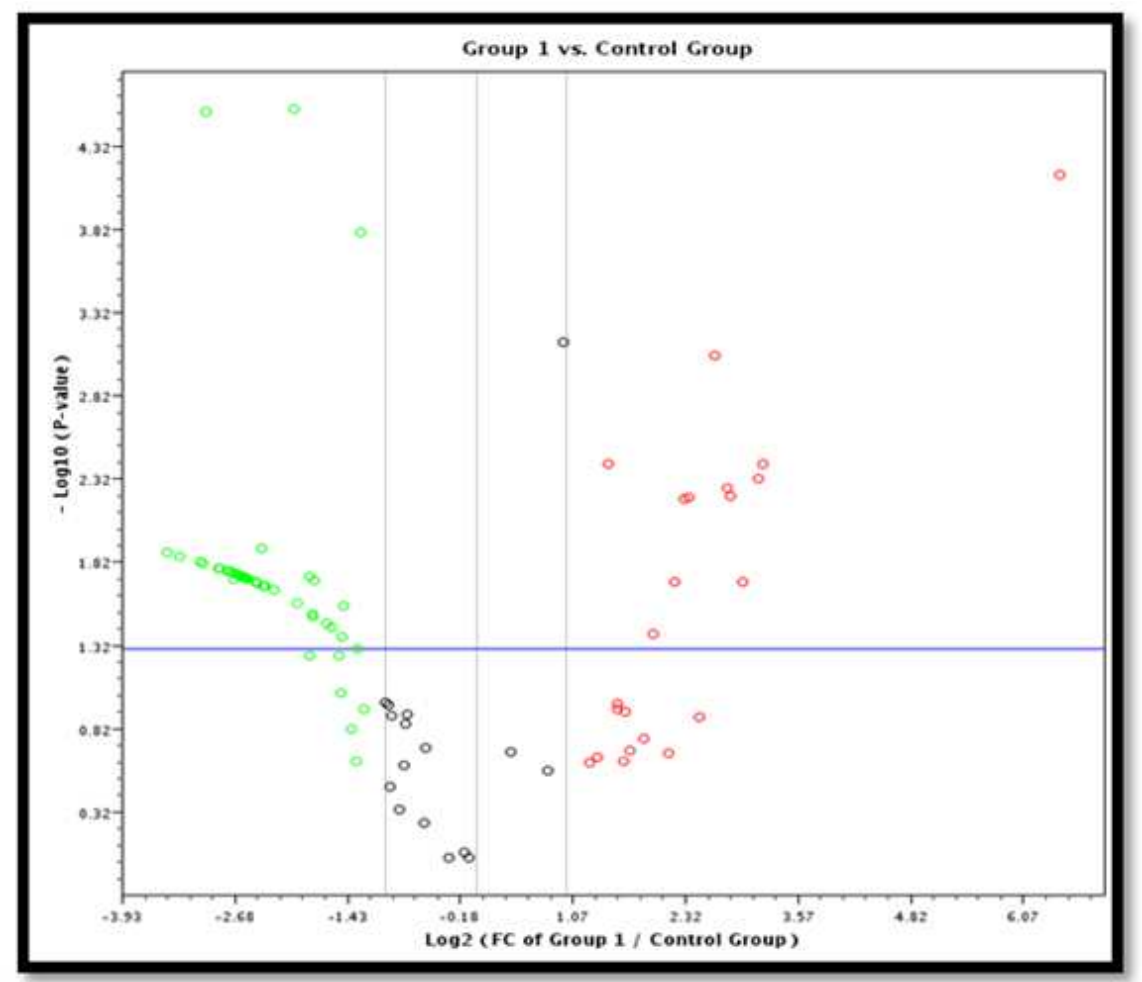

(A) 


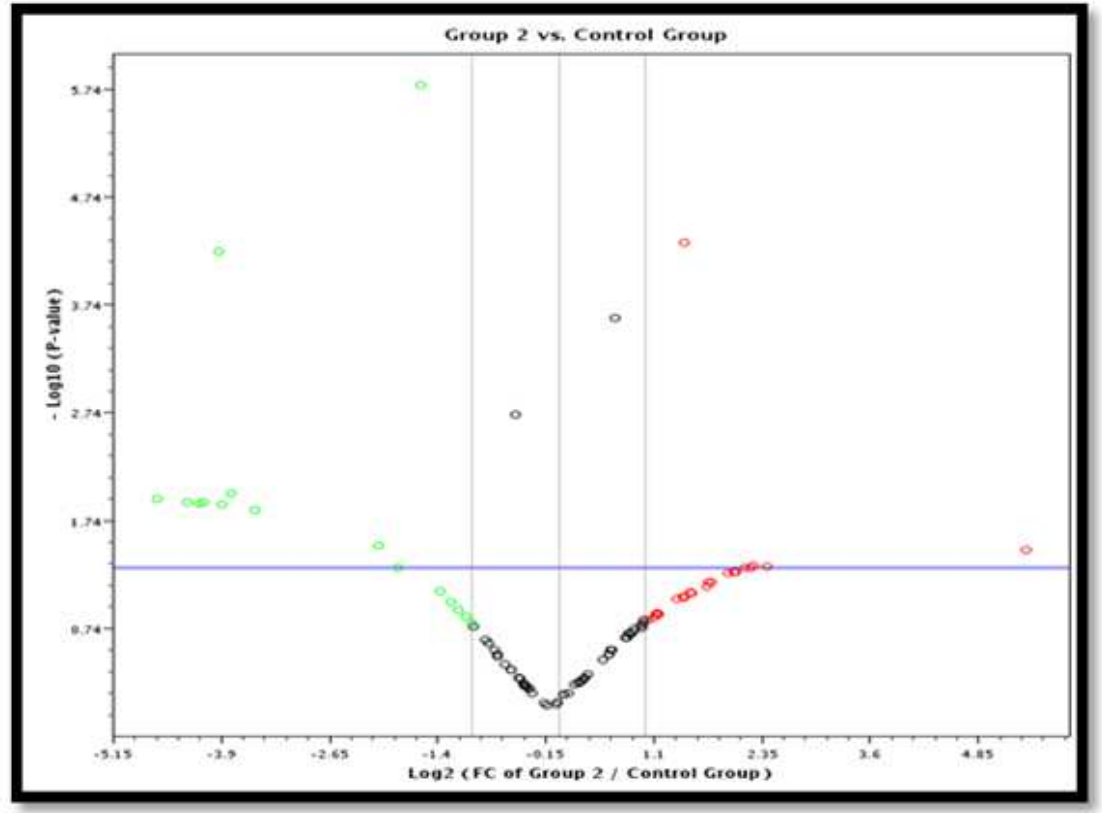

(B)

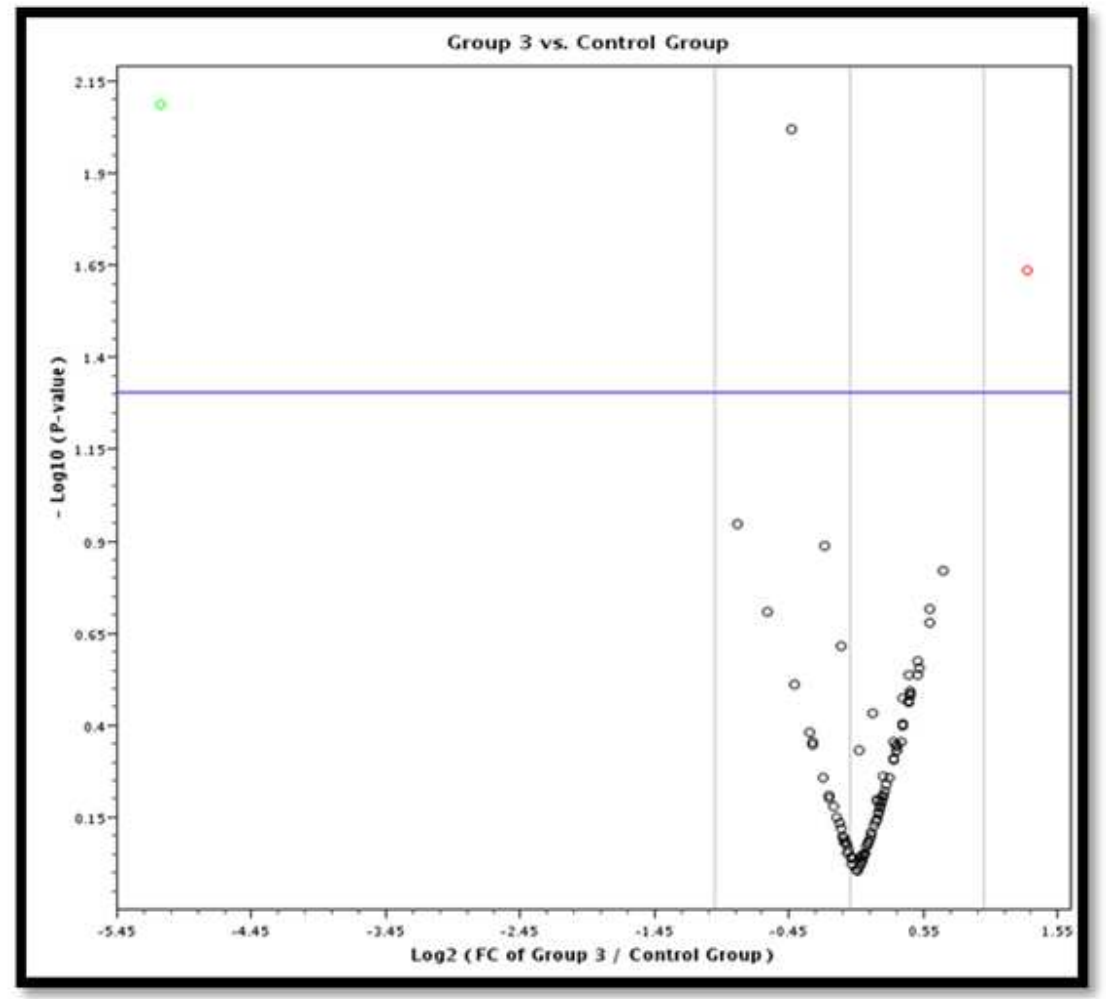

(C)

Fig. 2. The volcano plot of DNA repair gene expression among group I (A),group II (B) and group II (C) versus control group. The volcano plot displays statistical significance versus fold-change on the $\mathrm{y}-(-\log 10 \mathrm{p}$-value $)$ and $\mathrm{x}-(\log 2 \mathrm{FC}$ of groups/control group) axes, respectively. The volcano plot combines a p-value statistical test with the fold regulation change enabling identification of genes with both large and small expression changes that are statistically significant. Red circles indicate up regulated genes, green circles indicate down regulated genes while black ones indicate no change. As regards to significance, the circles those lie above the central line indicate significant $(\mathrm{p}<0.05)$ but those below the line indicate non significant $(\mathrm{p}>0.05)$ 
Gene Expression Regulation in Groupl (CpG Treated Group)

There are down regulation of 62 gene with significance for $52(\mathrm{p}<0.05)$ and significant up regulation of the remaining 22 genes (Table 1 and Fig. 2A).

\section{Gene Expression Regulation in Group2 (Cisplatin} Treated Group)

There are gown regulation of 40 genes with significance for $16(p<0.05)$, up regulation of 44 genes with significance for 24 genes (Table 1 and Fig. 2B).

\section{Gene Expression Regulation in Group3 (Combined $C p G$ and Cisplatin Treated Group)}

We observed in this group that there are no changes in gene expression compared to controls except Parp3 gene was significantly down regulated and significant up regulation in Lig 4 gene (Table 1 and Fig. 2C).

\section{Discussion}

CpG oligodeoxynucleotides) are considered to be promising immunomodulators and have been developed for clinical applications (Iho et al., 2015). So, is the CpG ODN able to protect the immune cells from apoptotic effect of chemotherapy? We assume for this ability was through modulation in DNA repair gene expression in immune cells and our results were in agreement with this hypothesis.

According to Kiyohara and Ohno (2010), Female mice were used in this study as DNA repair capacity was found to be lower in female than in their male counterparts that could supply more accurate data. This different capacity may be due to different levels of many hormones in males and females that many of them are powerful regulators in gene expression (Kiyohara and Ohno, 2010). Also, females have lower DNA repair capacity in lymphocytes in cancer patients (Regitz-Zagrosek and Seeland, 2012).

\section{Group I (Treated with CpG ODN)}

This study demonstrated that CpG-ODN caused significant up regulation in 22 DNA repair genes. That upon detecting the presence of an infectious agent via endosomal TLRs, immune cells might up-regulate DNA repair genes to decrease their susceptibility to possible pro apoptotic signals during infections (Sommariva et al., 2011). Also TLR-9 pathway was demonstrated to modulate the expression of DNA repair genes. Whereas TLR-9 agonists (CpG-ODN) reduced the expression of DNA repair in cancer cells, the same genes were up-regulated in immune cells (Melisi et al., 2014) and (Kutikhin and Yuzhalin, 2015).
Harberts and Gaspari (2013), suggested mechanisms by which TLR signaling might result in increased DNA repair. The promoter regions of genes contain at least one putative Activator Protein-1 (AP-1) binding site which is a transcription factor known to be induced by TLR signaling and the existence of its binding sites in promoter regions of many DNA repair genes suggests evidence of an association between TLR signaling and increased functional DNA repair (Harberts and Gaspari, 2013).

While, Kutikhin et al. (2014) suggest that $\mathrm{CpG}$ DNA, a legend for TLR9, encoded by myeloid differentiation primary response gene 88 (MyD88) may cause the activation of genes responsible for DNA repair mediated by Chk1/2 and ATM/ATR via MyD88-dependent pathway.

Mismatch Repair (MMR) pathway is an important repair mechanism in normal lymphocyte development as evidenced by mouse models and human patients deficient in this pathway. Msh3 gene deregulation in lymphomas has also illustrated the potential role of this pathway in Nthll that may explain its up regulation after the immunostimulation effect of $\mathrm{CpG}$ ODN treatment (Schuetz et al., 2013).

XRCC4 is connected to immunoglobulin Class Switch Recombination (CSR) as B lymphocyte restricted deletion of XRCC4 in mice lead to an average two-fold reduction in CSR in vivo and in vitro (Soulas-Sprauel et al., 2007). Then Almejun et al. (2013) group found that CSR is elicited by inducing of MyD88 and CpG- DNA. So, $\mathrm{CpG}$ ODN can modulate XRCC4 gene expression in indirect pathway.

The over expression of Xrcc6bp1 may be mediated by many mechanisms including binding to ku70 through co-immuno precipitation of FLAG-KUB3 and Ku70 protein using COS1 cells. So may be the immunomodulation that caused by administration of CpG ODN was the cause of Xrcc6bpl over expression (Fischer et al., 2013).

On the other hand, CpG-ODN treated mice showed significant down regulation in 52 genes and non significant down regulation in the rest genes. That is guiding us to say that the prominent effect of CpG-ODN one DNA repair genes was down regulation in their gene expression.

Klaschik's group who worked on normal spleen cells and show gene expression through $8 \mathrm{~h}$ after CpG ODN treatment, noted that while the absolute number of genes contributing to various immune responses increases over time, the fraction of the activated gene pool associated with the induction of an immune response decreases over time. The immune activation triggered by CpG DNA is rapid but of short duration. So, they suggest that gene activation may be down-regulated by a suppressive network (Klaschik et al., 2007). 
As a proof to their suggest, $\mathrm{Li}$ study found that $\mathrm{CpG}$ ODN can stimulate Th1 to secrete TNF- $\alpha$ in the early stage, but when the concentration of TNF- $\alpha$ is too high, it can stimulate $\mathrm{CpG}$ ODN to inhibit the secretion of Th1 and to promote the secretion of Th2, CpG ODN can maintain the balance of Th1/Th2. Thus, TNF- $\alpha$ concentrations increased on days 1 and 5 , but TNF- $\alpha$ concentrations declined rapidly on days 15 and 30 (Li et al., 2016).

Also, there were important differences in the type and behavior of genes activated in the early vs. late peak of gene activation. Time course and regulation of $\mathrm{CpG}$ induced changes in gene expression as gene activation peaked $3 \mathrm{~h}$ after $\mathrm{CpG}$ ODN administration and gradually declined over the next 3 days and then a second peak of gene activation was observed on day 5 , which slowly declined towards background by day 14. "Cell cycle regulation" and "DNA damage response" pathways genes expression began on days 3-5, remained high through day 7 and then fell progressively through day 14 (Klaschik et al., 2010).

So, we suggest that down regulation of some DNA repair genes expression may be due to time element as time course can cause changes in gene expression. While, the persistent up regulation of some DNA repair genes expression may be due to their direct or indirect connection with CpG-ODN activation pathway or their involvement in some other immune mechanisms.

\section{Group II (Treated by Cisplatin)}

In this group the up regulated genes observed in Cisplatin treated animals confirmed that DNA repair is the first barrier in the defense against genotoxic stress as in Cisplatin. So, in case of genotoxic insults, DNA repair genes have to be appropriately activated and up regulated. Activation by genotoxin-induced DNA damage has been reported for many repair genes including Apex1, Xrcc1, Errc1, Poll and Lig1. Their induction involves multiple players of the DNA damage response such as Ataxia Telangiectasia Mutated (ATM), ATM and PARP1 as well as key transcription factors. They observed $f$ up regulation of individual genes, but not all of them (Christmann and Kaina, 2013).

Basu and Krishnamurthy (2010), confirmed the role of Nucleotide Excision Repair Pathway (NER) in response to Cisplatin treatment since the intra strand cross-link is the major lesion caused by Cisplatininduced DNA damage; it is primarily repaired via the Nucleotide Excision Repair (NER) system. They also stated that the Cisplatin-induced DNA repair employing the NER process is multilayered including epigenetic, transcriptional and posttranslational regulation. NER is also linked to the cellular signaling pathways. It has been reported that the NER process may prevent Cisplatininduced apoptosis by activating the Ataxia Telangiectasia Mutated (ATM) pathway (Basu and Krishnamurthy, 2010).
While, Amable (2016) stated that there is an up regulation of NER genes that correlates with Cisplatin resistance. While the majority of the studies have focused on ERCC1, which up regulated in our study but not reach to a significant level, there are other NER genes additionally up regulated in patients who responded to Cisplatin therapy. That is explained the up regulation in Ercc 8, Lig 1, Rpa 1gene expression in our study (Amable, 2016).

Ataxia Telangiectasia mutated protein kinase ATM is activated in cells during the early response to DNA damage. Also ATM is activated by DSBs induced by Cisplatin (Weber and Ryan, 2015).

Cisplatin-induced toxicity may be mediated by the ability of the platinating agent to increase formation of Reactive Oxygen Species (ROS). An increase in ROS could result in oxidative DNA damage. The Base Excision Repair (BER) pathway is the major pathway for correctly repairing oxidative DNA induced damage. Within this pathway, a purinic/a pyrimidinic endonuclease/redox effectors factor (APE1) is a critical enzyme that is essential for repair by cutting the DNA backbone at baseless sites (a basic) in DNA after the removal of the damage base. That may explain the up regulation in Apexl gene expression, also the up regulation in Parpl and Tdg which involved in BER pathway (Kelley et al., 2014).

Cisplatin produces platinum adducts and oxidative DNA damage and the repair of these insults to DNA are mitigated by APE1 in the BER pathway and interactions with the NER pathway, mainly proteins involved in early steps of NER as RPA1. So, RPA1 gene expression upregulation in our work may relate indirectly to the upregualtion of Apex1 gene expression (Kim et al., 2015).

XRCC6 is a member of DNA-dependent Protein Kinase complex (DNA-PK) which is activated in response to DNA damage and participates in non-homologous end joining and V(D)J recombination. That may explain the up regulation of XRCC6 binding protein 1 gene expression after cisplatin treatment (Chavez et al., 2011).

On the other hand, in our study, group I which treated with cisplatin showed that there are significant down regulation in (Ercc3, Msh3, Msh6, Pold3, Brca1, Prkdc and Rad51d) genes expression $(\mathrm{p}<0.05)$.

The repair function of MMR proteins is uncoupled from their function in mediating Cisplatin-induced cell death. Since the primary mechanism of Cisplatin involves DNA damage and p53 is also involved in DNA damage signaling. Cisplatin enhances the interaction between mismatch repair proteins and p53 triggering apoptosis in mismatch repair-proficient cells (Basu and Krishnamurthy, 2010).

Several lines of evidence indicated that Cisplatin resistance can be attributed to increased DNA repair. 
Interestingly, the deficiency or down regulation of MMR components was resulted in Cisplatin resistance. MMR proteins have been shown to directly signal the DNA damage, eventually resulting in cell death (Kothandapani et al., 2013). So, our results indicate development of Cisplatin resistance that its main indicator is MMR pathway (Msh3, Msh6 and Pold3).

Also, $\mathrm{Xu}$ et al. (2015) reported that the different MSH3 polymorphisms have a respectively different effect on chemotherapy sensitivity and survival. They suggest that MSH3 may modulate DNA repair capacity and contribute to individual variations in platinum-based chemotherapy response and prognosis.

MSH3 is required for the repair of DNA Double Strand Breaks (DSBs) induced during Cisplatin treatment. MSH3 can enable HR to repair DSBs through Rad51 and Brca genes. That is why the down regulation of Rad51d and Brcal could be secondary to the down regulation of Msh3 (Park et al., 2013).

Also, Pol $\delta$ act as the repair polymerase in MMR which mainly involved in Cisplatin resistance. That explains the down regulation in Pol $\delta$ gene expression (Prindle and Loeb, 2012).

Beside promoter activation by transcription factors, an alternative process to achieve up regulation of DNA repair genes rests on de-repression of a silenced promoter. Key factor for that pathway is specificity protein 1 ( $\mathrm{Sp} 1$ ), which can be sequestered by $\mathrm{p} 53$, thus reducing gene basal expression. Many DNA repair genes were regulated by Sp1 including MSH6 and XRCC3 (Christmann and Kaina, 2013).

The exposure to Cisplatin resulted in differential expression of genes associated with cell growth and proliferation, cellular assembly, cell death, cell cycle control and cell signaling (L'Espérance et al., 2008). Genes implicated in signal transduction, immune and inflammatory response and transcription regulation were commonly suppressed following Cisplatin treatment. That may explain BRCA1 down regulation, as BRCA1 involved in signal transduction and transcription regulation beside its DNA repair functions (Vincent et al., 2016).

PRKDC is a critical component of DNA repair machinery that plays a pivotal role in the DNA Damage Response (DDR) and maintenance of genomic stability (Sun et al., 2016). Despite its role in DDR, PRKDC is found to be associated with poor prognosis independent of damage induction in numerous tumor types. Down regulation of PRKDC sensitized cancer cells to chemotherapy (Munck et al., 2012).

So, we suggest that up regulation of some DNA repair genes expression after Cisplatin treatment may be as a part of DNA damage response as DNA is thought to be the primary biological target of Cisplatin. While, the down regulation of some other genes may be due to rise of some sort of resistance to Cisplatin or their involvement in other cellular pathways beside DNA repair that lead the cell toward apoptosis.

\section{Group III (Treated with Cisplatin and CPG-ODN)}

In our study, group III which treated with Cisplatin and CPG-ODN showed that there are slight changes in the DNA repair genes expression but not reach to significant level except for LIG4 gene expression which is significantly up regulated. Also, we observed that the genes expression of this group is nearly around the same level of genes expression of control group.

DNA Ligase 4 (LIG4) is a key factor in the NonHomologous End-Joining (NHEJ) DNA double-strand break repair pathway needed for $\mathrm{V}(\mathrm{D}) \mathrm{J}$ recombination. The V(D)J recombination process is specific for lymphocytes and mandatory for $\mathrm{T}$ and $\mathrm{B}$ cell development (Felgentreff et al., 2016). That may explain its up regulation in the combined therapy as LIG4 act as a bridge between DNA damage response by DNA repair and the immune system, so, CpG-ODN and Cisplatin act in a synergetic action on this gene.

The up regulation or down regulation of DNA repair may represent a molecular biological explanation for the synergy seen when chemotherapy is administered with TLR agonists (Harberts and Gaspari, 2013).

Some preclinical models suggested that TLR-9 agonists can synergize with cytotoxic chemotherapy. TLR-9 recently emerged as a potential therapeutic target for its ability to present non-self-antigens to adaptive immune cells and to stimulate the production of mediators with a direct antitumor activity. Solid preclinical evidence had been provided to support multiple mechanisms of action for TLR-9 agonists, either on tumor, endothelial and immune cells, suggesting that this class of agent may play an antitumor role (Melisi et al., 2014).

CpG-ODN induced modulation of a cohort of DNA repair genes that cooperatively influence the ability of cells to repair drug-induced DNA damage. The combination of Cisplatin and CpG-ODN to treat ovarian tumor xenografts growing in the peritoneal cavity of athymic mice induced a remarkable increase in lifespan compared with that using either reagent alone (Sommariva et al., 2012).

While Sandholm and Selander (2014), reported that TLR9 is required for chemotherapy-induced anti-tumor immune response. CpG-ODNs have demonstrated promising immune system-mediated anti-cancer effects against breast cancer in preclinical models. TLR9mediated inflammation caused by chemotherapy might then amplify the anti-tumor immune response (Sandholm and Selander, 2014).

The conventional chemotherapy is widely known to cause lympho-depletion and immune-suppression, a 
factor that could undermine immunotherapy in combined treatment regimens. However, a part of the antitumor effects of platinum drugs occurs through modulation of the immune system. So, combining low dose chemotherapy with immunotherapy was suggested for better outcome (Jordan and Waxman, 2016).

\section{Conclusion}

So, we suggest that as $\mathrm{CpG}$ ODN and cisplatin are overlapped and share some intrinsic pathways through their mode of action, they may work in synergetic way. While cisplatin induces DNA damages to as a part of its cytotoxic effect, $\mathrm{CpG}$ ODN induces immunomodulation that help to decrease the side effects caused by Cisplatin cytotoxicity.

Moreover, CpG-ODN neutralize the DNA damage effect caused by Cisplatin that may explain why almost all DNA repair genes expression in group III (CpG-ODN and Cisplatin) are around the same level of DNA repair genes expression in control group.

\section{Recommendation}

In the future plan, we recommended further many studies using the same technique but with different cancer types and CpG-ODN doses with chemotherapy to specify the types of genes modulated mainly in each type of cancer and the proper dose of CpG-ODN in addition to the actually effective manner of combined therapy treatment.

\section{Acknowledgement}

Special thanks to Molecular Biology Unit staff members.

\section{Author's Contributions}

Naglaa Fathy Alhusseini: Established the PCR array technique, analysis and interpretation of results, contributed unpublished essential data, writing the manuscript and corresponding author.

Amal Abo El-Fadl: Supervision on the research steps and revision of the article.

Shabaan Hemada: Conception and design, supervision on the experimental research steps.

Mohamed E. Abo Salem: Supervision on the research steps.

Yasmin Marai and Olla Khalifa: Experimental animal handling, collecting samples and research data, collecting the scientific materials and application of the experiment.

Amal Idris: Design the experiment, supervision of all the research steps and article reviewer.

\section{Ethics}

We confirm that this manuscript has not been published elsewhere and is not under consideration by any other journal. The authors confirm the manuscript represents honest work. All authors have approved the manuscript. Each author agrees with the order in which his name appears on the title page. Study design and methods were approved by Ethics Committee of Benha Faculty of Medicine.

\section{References}

Ahmad, I., E. Simanyi, P. Guroji, I.A. Tamimi and H.J. Delarosa et al., 2014. Toll-like receptor-4 deficiency enhances repair of UVR-induced cutaneous DNA damage by nucleotide excision repair mechanism. J. Invest. Dermatol., 134: 1710-710. DOI: $1038 /$ jid.2013.530

Almejun, M.B., M. Cols, M. Zelazko, M. Oleastro and A. Cerutti et al., 2013. Naturally occurring mutation affecting the MyD88-binding site of TNFRSF13B impairs triggering of class switch recombination. Eur. J. Immunol., 43: 805-814.

DOI: $10.1002 /$ eji.201242945

Amable, L., 2016. Cisplatin resistance and opportunities for precision medicine. Pharmacol. Res., 106: 27-36. DOI: 10.1016/j.phrs.2016.01.001

Apps, M.G., E.H.Y. Choi and N.J. Wheate, 2015. The state-of-play and future of platinum drugs. Endocrine-related Cancer, 22: 219-233. PMID: 26113607

Basu, A. and S. Krishnamurthy, 2010. Cellular responses to Cisplatin-induced DNA damage. J. Nucleic Acids, 2010: 201367-201367. DOI: $10.4061 / 2010 / 201367$

Caldecott, K.W., 2008. Single-strand break repair and genetic disease. Nat. Rev. Genet., 9: 619-631. DOI: $10.1038 / \mathrm{nrg} 2380$

Chavez, J.D., M.R. Hoopmann, C.R. Weisbrod, K. Takara and J.E. Bruce, 2011. Quantitative proteomic and interaction network analysis of cisplatin resistance in HeLa cells. PLoS One, 6: e19892-e19892. DOI: 10.1371/journal.pone.0019892

Christmann, M. and B. Kaina, 2013. Transcriptional regulation of human DNA repair genes following genotoxic stress: Trigger mechanisms, inducible responses and genotoxic adaptation. Nucleic Acids Res., 41: 8403-8420. DOI: $10.1093 /$ nar/gkt635

Dasari, S. and P.B. Tchounwou, 2014. Cisplatin in cancer therapy: Molecular mechanisms of action. Eur. J. Pharmacol., 740: 364-378.

DOI: 10.1016/j.ejphar.2014.07.025 
De Cesare, M., L. Sfondrini, M. Campiglio, M. Sommariva and F. Bianchi et al., 2010. Ascites regression and survival increase in mice bearing advanced-stage human ovarian carcinomas and repeatedly treated intraperitoneally with CpG-ODN. J. Immunother., 33: 8-15. DOI: 10.1097/CJI.0b013e3181affaa7

De Cesare, M., L. Sfondrini, M. Pennati, C. De Marco and V. Motta et al., 2016. CpGoligodeoxynucleotides exert remarkable antitumor activity against diffuse malignant peritoneal mesothelioma orthotopic xenografts. J. Transl. Med., 14: 25-25. DOI: 10.1186/s12967-016-0781-4

Felgentreff, K., S.N. Baxi, Y.N. Lee, K. Dobbs and L.A. Henderson et al., 2016. Ligase-4 deficiency causes distinctive immune abnormalities in asymptomatic individuals. J Clin. Immunol., 36: 341-453. DOI: 10.1007/s10875-016-0266-5

Fischer, U., S. Rheinheimer, A. Krempler, M. Lbrich and E. Meese, 2013. Glioma-amplified sequence KUB3 influences double-strand break repair after ionizing radiation. Int. J. Oncol., 43: 50-56. DOI: $10.3892 /$ ijo.2013.1937

Ganguly, B., S.C. Dolfi, L. Rodriguez-Rodriguez, S. Ganesan and K.M. Hirshfield, 2016. Role of biomarkers in the development of PARP inhibitors. Biomark Cancer, 8: 15-25. DOI: $10.4137 /$ BIC.S36679

Harberts, E. and A.A. Gaspari, 2013. TLR signaling and DNA repair: Are they associated? J. Invest. Dermatol., 133: 296-302. DOI: 10.1038/jid.2012.288

Hepel, M., M. Stobiecka, J. Peachey and J. Miller, 2012. Intervention of glutathione in pre-mutagenic catechol-mediated DNA damage in the presence of copper(II) ions. Mutat. Res., 735: 1-11. DOI: $10.1016 / \mathrm{j} . \mathrm{mrfmmm} .2012 .05 .005$

Holohan, C., S. Van Schaeybroeck, D.B. Longley and P.G. Johnston, 2013. Cancer drug resistance: An evolving paradigm. Nat. Rev. Cancer, 13: 714-726. DOI: $10.1038 / \mathrm{nrc} 3599$

Iho, S., J. Maeyama and F. Suzuki, 2015. CpGoligodeoxynucleotides as mucosal adjuvants. Hum. VaccinImmunother, 11: 755-760. DOI: $10.1080 / 21645515.2014 .1004033$

Ilkhania, H., T. Hughesa, J. Lib, C.J. Zhongb and M. Hepel, 2016. Nanostructured SERSelectrochemical biosensors for testing of anticancer drug interactions with DNA. Biosensors Bioelectron., 80: 257-264. DOI: 10.1016/j.bios.2016.01.068

Jackson, S.P. and J. Bartek, 2009. The DNA-damage response in human biology and disease. Nature, 461: 1071-1078. DOI: 10.1038 /nature08467

Jiang, Y., X. Meng, Z. Wu and X. Qi, 2016. Modified chitosan thermosensitive hydrogel enables sustained and efficient anti-tumor therapy via intratumoral injection. Carbohydrate Polymers, 144: 245-253. DOI: 10.1016/j.carbpol.2016.02.059
Jordan, M. and D.J. Waxman, 2016. CpG-1826 immunotherapy potentiates chemotherapeutic and anti-tumor immune responses to metronomic cyclophosphamide in a preclinical glioma model. Cancer Lett., 373: 88-96.

DOI: $10.1016 /$ j.canlet.2015.11.029

Kelley, M.R., Y. Jiang, C. Guo, A. Reed and H. Meng et al., 2014. Role of the DNA base excision repair protein, APE1 in cisplatin, oxaliplatin, or carboplatin induced sensory neuropathy. PLoS One, 9: e106485-e106485.

DOI: 10.1371/journal.pone.0106485

Kim, H.S., C. Guo, E.L. Thompson, Y. Jiang and M.R. Kelley et al., 2015. APE1, the DNA base excision repair protein, regulates the removal of platinum adducts in sensory neuronal cultures by NER. Mutat. Res., 779: 96-104.

DOI: $10.1016 /$ j.mrfmmm.2015.06.010

Kiyohara, C. and Y. Ohno, 2010. Sex differences in lung cancer susceptibility: A review. Gend. Med., 7: 381-401. DOI: 10.1016/j.genm.2010.10.002

Klaschik, S., D. Tross, H. Shirota and D.M. Klinman, 2010. Short- and long-term changes in gene expression mediated by the activation of TLR9. Mol. Immunol., 47: 1317-1324.

DOI: $10.1016 /$ j.molimm.2009.11.014

Klaschik, S., I. Gursel and D.M. Klinman, 2007. CpGmediated changes in gene expression in murine spleen cells identified by microarray analysis. Mol. Immunol., 44: 1095-104. PMID: 16930709

Kothandapani, A., A. Sawant, V.S. Dangeti, R.W. Sobol and S.M. Patrick, 2013. Epistatic role of base excision repair and mismatch repair pathways in mediating cisplatin cytotoxicity. Nucleic Acids Res., 41: 7332-7343. DOI: 10.1093/nar/gkt479

Kutikhin, A.G. and A.E. Yuzhalin, 2015. Editorial: Pattern recognition receptors and cancer. Front Immunol., 6: 481-481. DOI: $10.3389 /$ fimmu.2015.00481

Kutikhin, A.G., A.E. Yuzhalin, E.A. Tsitko and E.B. Brusina, 2014. Pattern recognition receptors and DNA repair: Starting to put a jigsaw puzzle together. Front Immunol., 5: 343-343.

DOI: $10.3389 /$ fimmu.2014.00343

L'Espérance, S., M. Bachvarova, B. Tetu, A.M. Mes-Masson and D. Bachvarov, 2008. Global gene expression analysis of early response to chemotherapy treatment in ovarian cancer spheroids. BMC Genomics, 9: 99-99. DOI: 10.1186/1471-2164-9-99

Li, X., G. Xu, T. Qiao, S. Yuan and X. Zhuang, 2016, Effects of CpGoligodeoxynucleotide 1826 on acute radiation-induced lung injury in mice. Biol. Res., 49: 8-8. DOI: 10.1186/s40659-016-0068-5

Livak, K.J. and T.D. Schmittgen, 2001. Analysis of relative gene expression data using real-time quantitative PCR and the 2(-Delta Delta C(T)) method. Methods, 25: 402-408. PMID: 11846609 
Melisi, D., M. Frizziero, A. Tamburrino, M. Zanotto and C. Carbone et al., 2014. Toll-like receptor 9 agonists for cancer therapy. Biomedicines, 2: 211-228. DOI: 10.3390/biomedicines2030211

Munck, J.M., M.A. Batey, Y. Zhao, H. Jenkins and C.J. Richardson et al., 2012. Chemosensitization of cancer cells by KU-0060648, a dual inhibitor of DNAPK and PI-3 K. Mol. Cancer Ther., 11: 1789-1798. DOI: $10.1158 / 1535-7163 . M C T-11-0535$

Park, J.M., S. Huang, D. Tougeron and F.A. Sinicrope, 2013. MSH3 mismatch repair protein regulates sensitivity to cytotoxic drugs and a histone deacetylase inhibitor in human colon carcinoma cells. PLoS One, 8: e65369-e65369. DOI: 10.1371/journal.pone.0065369

Prindle, M.J. and L.A. Loeb, 2012. DNA polymerase delta in DNA replication and genome maintenance. Environ. Mol. Mutagen, 53: 666-682. DOI: $10.1002 / \mathrm{em} .21745$

Regitz-Zagrosek, V. and U. Seeland, 2012. Sex and gender differences in clinical medicine. Handb. Exp. Pharmacol., 214: 3-22.

DOI: $10.1007 / 978-3-642-30726-3 \quad 1$

Salomoni, P., 2013. Reprogramming and genome integrity: role of non homologous end joining. Cell Death Differ, 20: 1285-1286. DOI: $10.1038 /$ nrg2380

Sandholm, J. and K.S. Selander, 2014. Toll-like receptor 9 in breast cancer. Front Immunol., 5: 330-330. DOI: $10.3389 /$ fimmu.2014.00330

Schuetz, J.M., D. Daley, S. Leach, L. Conde and B.R. Berry et al., 2013. Non-hodgkin lymphoma risk and variants in genes controlling lymphocyte development. PLoS One, 8: e75170-e75170. DOI: $10.1371 /$ journal.pone.0075170

Sommariva, M., L. De Cecco, E. Tagliabue and A. Balsari, 2012. Modulation of DNA repair genes induced by TLR9 agonists: A strategy to eliminate "altered" cells? Oncoimmunology, 1: 258-259. PMID: 22720263

Sommariva, M., L. De Cecco, M. De Cesare, L. Sfondrini and S. Ménard et al., 2011. TLR9 agonists oppositely modulate DNA repair genes in tumor versus immune cells and enhance chemotherapy effects. Cancer Res., 71: 6382-6390.

DOI: 10.1158/0008-5472.CAN-11-1285

Sommariva, M., M. de Cesare, A. Meini, A. Cataldo and N. Zaffaroni et al., 2013. High efficacy of CpGODN, cetuximab and cisplatin combination for very advanced ovarian xenograft tumors. J. Transl. Med., 11: 25-25. DOI: $10.1186 / 1479-5876-11-25$
Soulas-Sprauel, P., G. Le Guyader, P. Rivera-Munoz, V. Abramowski and C. Olivier-Martin et al., 2007. Role for DNA repair factor XRCC4 in immunoglobulin class switch recombination. J. Exp. Med., 204: 1717-1727. PMID: 17606631

Stordal, B. and M. Davey, 2007. Understanding cisplatin resistance using cellular models. IUBMB Life, 59: 696-699. PMID: 17885832

Sun, S., S. Cheng, Y. Zhu, P. Zhang and N. Liu et al., 2016. Identification of PRKDC (Protein Kinase, DNA-activated, catalytic polypeptide) as an essential gene for colorectal cancer (CRCs) cells. Gene, 584: 90-96. DOI: 10.1016/j.gene.2016.03.020

Vincent, A., E. Berthel, E. Dacheux, C. Magnard and N.L. Venezia, 2016. BRCA1 affects protein phosphatase 6 signalling through its interaction with ANKRD28. Biochem. J., 473: 949-960. DOI: $10.1042 / \mathrm{BJ} 20150797$

Vollmer, J. and A.M. Krieg, 2009. Immunotherapeutic applications of CpGoligodeoxynucleotide TLR9 agonists. Adv. Drug. Deliv. Rev., 61: 195-204. DOI: $10.1016 /$ j.addr.2008.12.008

Wang, C., X.Q. Liu, J.S. Hou, J.N. Wang and H.Z. Huang, 2016. Molecular mechanisms of chemoresistance in oral cancer. Chin. J. Dent. Res., 19: 25-33. DOI: $10.3290 /$ j.cjdr.a35694

Weber, A.M. and A.J. Ryan, 2015. ATM and ATR as therapeutic targets in cancer. Pharmacol. Ther., 149: 124-138. DOI: 10.1016/j.pharmthera.2014.12.001

Xing, J., X. Qi, Y. Jiang, X. Zhu and Z. Zhang et al., 2014. Topotecan hydrochloride liposomes incorporated into thermosensitive hydrogel for sustained and efficient in situ therapy of H22 tumor in Kunming mice. Pharm. Dev. Technol., 9: 1-8.

Xu, X.L., Y.L. Yao, W.Z. Xu, J.G. Feng and W.M. Mao, 2015. Correlation of MSH3 polymorphisms with response and survival in advanced non-small cell lung cancer patients treated with first-line platinum-based chemotherapy. Genet Mol. Res., 14: 3525-3533. DOI: $10.4238 / 2015$

Yousef, M.M., N.F. Alhusseini, H.A. Mohamed, R. Eldesoky and M.M. Zaki, 2014. Role of ginger extract and $\mathrm{N}$-acetylcysteine in acute renal tubular necrosis: Histological, immunohistochemical and gene expression study in rats. Cell boil. Genet. J., 4: 27-39. DOI: 10.5897/JCBG2014.0038 . 